\title{
PESQUISA DE ANTICORPOS IgM ANTI-TOXOPLASMA GONDII POR MEIO DE TÉCNICA IMUNOENZIMATICA REVERSA
}

bosè Roberto MiNEO (*), Märio Endsfeidz CAMARCO, Autonio -Walter FERREIRA e Gastāo ALMEIDA

\section{R ES S M O}

Um teste imunoenzimático reverso foi padronizado utilizando-se como fase sólida, microplacas de polivinil sensibilizadas com anticorpos anti.IgM. Estas foram incubadas seqüencialmente com alíquotas de soros de pacientes com suspeita de toxoplasmose aguda, antígeno solúvel de Toxoplasma gondii, conjugado peroxidase-F $\left(\mathrm{ab}^{\prime}\right)_{2}$ anti-toxoplasma e substrato enzimático. A atividade enzimática loi determinada por leitura espectrofotométrica, considerando-se como titulos dos soros a máxima diluição fornecendo valores de absorbância maiores que os obtidos com a menor diluição do soro padrão não-reativo. Em 69 amostras de soros de pacientes com toxoplasmose aguda, a média geométrica dos títulos no teste ELISA-Reverso IgM foi superior à de todos os outros testes para anticorpos IgM, não se observando resultados negatjvos falsos devidos a altos titulos de IgG especifica. Não foi encontrada, também, reatividade cruzada em nenhuma das 104 amostras de soros de pacientes com outras patologias, inclusive em amostras contendo fator reumatóide IgM.

UNITERMOS: Toxoplasmose - Diagnóstico - Sorologia - Imunoenzimologia reversa.

\section{N T R O D U ÇA O}

O diagnóstico sorológıco da toxoplasmose se baseıa na correta interpretaçäo de mais de um teste, como a imunofluorescência indireta, hemaglutinação passiva e fixação de complemento ${ }^{\circ}$. A detecção da faşe aguda da infeç̧̧ão foi grandemente facilitada pela introdução de conjugados anti-imunoglobulina $M$ nos testes de imunofluorescència. No entanto, mesmo com a atual disponibilidade desses reagentes, a determinação sorológica da infecçăo tem encontrado algurnas limitaçōes. Resultados positivos falsos pudem ocorrer nos soros contendo anticorpos antinucleares ou fator reumatóide 1,2,7. Reaçôes negatıvas falsas ou fracamente positivas são verificadas nos suros apresentando altos títulos de anticorpos IgG com alta afinidade an- ti-toxoplasma, que competem com os anticorpos IgM na fixação aos determiantes antigênicos do parasita durante a primeira fase dos ensaios. Esses problemas têm sido parcialmente resolvidos pela inclusão, nos testes, de etapas que removem tanto o fator reumatóide, por adsorçâo a suspensōes de IgG insolubilizadas pelo glutaraldeido ou agregados pelo calor $\$, 7$, como as IgG do soro, por adsorçẳo pela pro: teína A do Staphylococcus aureus ${ }^{8}$.. Entretanto isto representa a introdução de etapas, envolvendo reagentes com disponibilidade relativamente restrita e de padronizaçăo ainda năo muito satisfatória, em testes conhecidos exatamente pela sua simplicidade e possibilidade de ampla aplicação.

Trabalho realizatio no Laboratório de Imumologis do Instituto de Medicina Tropical de São Paulo

(") Presente endereço: Departamento de Ciências Fumdamentais para a saúde, Universidađe Federal de Uberlândia, MG, Brasil, CEP 38400. 
MINEO, J. R.; CAMARGO, M. E.; FERREIRA, A. W. \& ALMEIDA, G. - Pesquisa de anticorpos IgM anti-Toxoplasma gondil por meio de técnica imunoenzimática reversa. Rev. Inst. Med. trop. São Paulo 28:6-11, 1986.

O presente trabalho descreve a aplicação de um teste imunoenzimático reverso para a detecção de anticorpos IgM anti-toxoplasma e estabelece comparação com outros testes sorológicos em termos de sensibilidade e especificidade.

\section{MATERIAL E METODOS}

\section{Amostras de soros}

Para o estudo da sensibilidade do teste ELISA-Reverso IgM, foram utilizadas 69 amostras de soros de pacientes com toxoplasmose aguda cuja caracterização sorológica foi determinada pelos testes imunofluorescência-IgG, imunofluorescência-IgM, fixação de complemento e hemaglutinação passiva, como descrito por CAMARGO \& col 6 . Estas amostras tinham sido também submetidas a outros testes sorológicos, como os testes imunoenzimáticos ELISAIgG e ELISA-IgM com antígeno protéico ${ }^{4}$ e com antigeno polissacarídico 12 . No estudo da especificidade do teste ELISA-Reverso IgM foram empregadas 104 amostras de soros de pacientes apresentando patologias diversas. Todas as amostras de soros tinham sido inativa. das a $56^{\circ} \mathrm{C}$ por 30 minutos e estavam armazenadas a $-20^{\circ} \mathrm{C}$ em glicerina neutra (E. Merck, Darmstadt), volume a volume, por um período compreendido entre 6 e 24 meses.

\section{Obtenção e purificação do anti-soro anti-IgM humana}

As imunoglobulinas da classe IgM, obtidas a partir do soro de paciente com mieloma $\mathbf{M}$, foram isoladas segundo método descrito por MICHELI \& ISLIKER 11. Escolheu-se para inoculação um carneiro que recebeu inicialmente 4 doses semanais de emulsão contendo $2 \mathrm{mg}$ de IgM e adjuvante completo de Freund, por via subcutânea, seguidas por mais 4 doses semanais de solução contendo $5 \mathrm{mg}$ de IgM, sem adjuvante, por via intramuscular. A purificação do soro de carneiro imunizado com IgM humana foi realizada por absorção com polímero de IgG humana, segundo a técnica descrita por AVRAMEAS \& TERNYNCK ${ }^{3}$.

\section{Obtenção do antígeno solúvel}

$\mathrm{O}$ antígeno solúvel do Toxoplasma gondii, cepa $\mathbf{R H}$, empregado no teste imunoenzimático reverso foi obtido segundo o mesmo processo descrito por CAMARGO \& col. ${ }^{6}$.

\section{Preparo do conjugado imunoenvimático}

O conjugado imunoenzimático utilizado consistiu do produto de ligação entre a peroxidase e o fragmento $F\left(a b^{\prime}\right)_{2}$ da IgG de coelhos imunizados com T. gondii. $\mathbf{O}$ método de conjugação empregado foi o de WILSON \& NAKANE ${ }^{14}$, utilizando-se enzima e digesto pepsínico na relaçäo ponderal 1:1.

\section{Padronização dos testes}

Os ensaios imunoenzimáticos foram realizados em placas de polivinil (Plásticos Ampla Ind. Com. Ltda., SP) sendo as superfícies plásticas sensibilizadas por meio de incubação de 18 horas a $4^{\circ} \mathrm{C}$ com a fração IgG do soro de carneiro imunizado com IgM humana, diluida em tampão carbonato $0,06 \mathrm{M}$ pH 9,6. As placas sensibilizadas foram lavadas 3 vezes por $5 \mathrm{mi}$ nutos em PBS-Tween 20 e incubadas com os soros testes e soros padróes nas diferentes diluições, variando de $1 / 16$ a 1/262144. Após incubação de 1 hora a $37^{\circ} \mathrm{C}$, as placas foram lavadas em PBS-Tween 20 e incubadas com antigeno solúvel de T. gondii por 1 hora a $37^{\circ} \mathbf{C}$. Após lavagens em PBS-Tween 20, as placas foram incubadas por 1 hora a $37^{\circ} \mathrm{C}$ com o con. jugađo imunoenzimático. Ađicionou-se, então, após nova série de lavagens, o substrato revelador formado por soluçāo de peróxido de hidrogênio 1,5 mM e ácido 5-aminosalićlico 5,2 $\mathrm{mM}$, sendo o produto formado quantificado por leitura espectrofotométrica a $450 \mathrm{~nm}$.

\section{R E S U T A D O S}

\section{Titulação dos reagentes no ensaio imunoenvi-} mático

O efeito das diferentes concentraçōes do antígeno de toxoplasma em função das diferentes quantidades do anti-soro anti-IgM, fixadas em fase sólida, está representado na Fig. 1. Observou-se que o anti-soro utilizado na concentração protéica de $100 \mu \mathrm{g} / \mathrm{ml}$ nāo đifere significativamente do utilizado na concentração de $\mathbf{3 0 0}$ $\mu \mathrm{g} / \mathrm{ml}$, optando-se pela solução mais diluida. A concentração considerada ótima do antígeno foi a de $200 \mu \mathrm{g} / \mathrm{ml}$. Através da titulação em bloco, verificou-se que o título ótimo observado para o conjugado foi $1 / 200$, considerando-se também a concentração do antígeno de $200 \mu \mathrm{g} / \mathrm{ml}$. 
MINEO, J. R.; CAMARGO, M. E.; FERREIRA, A. W. \& ALMEIDA, G. - Pesquisa de anticorpos IgM anti-Toxoplasma gandil por meio de técnica imunoenzimnática reversa. Rev. Inst, Med. trop. São Paulo 28:6-11, 1986.

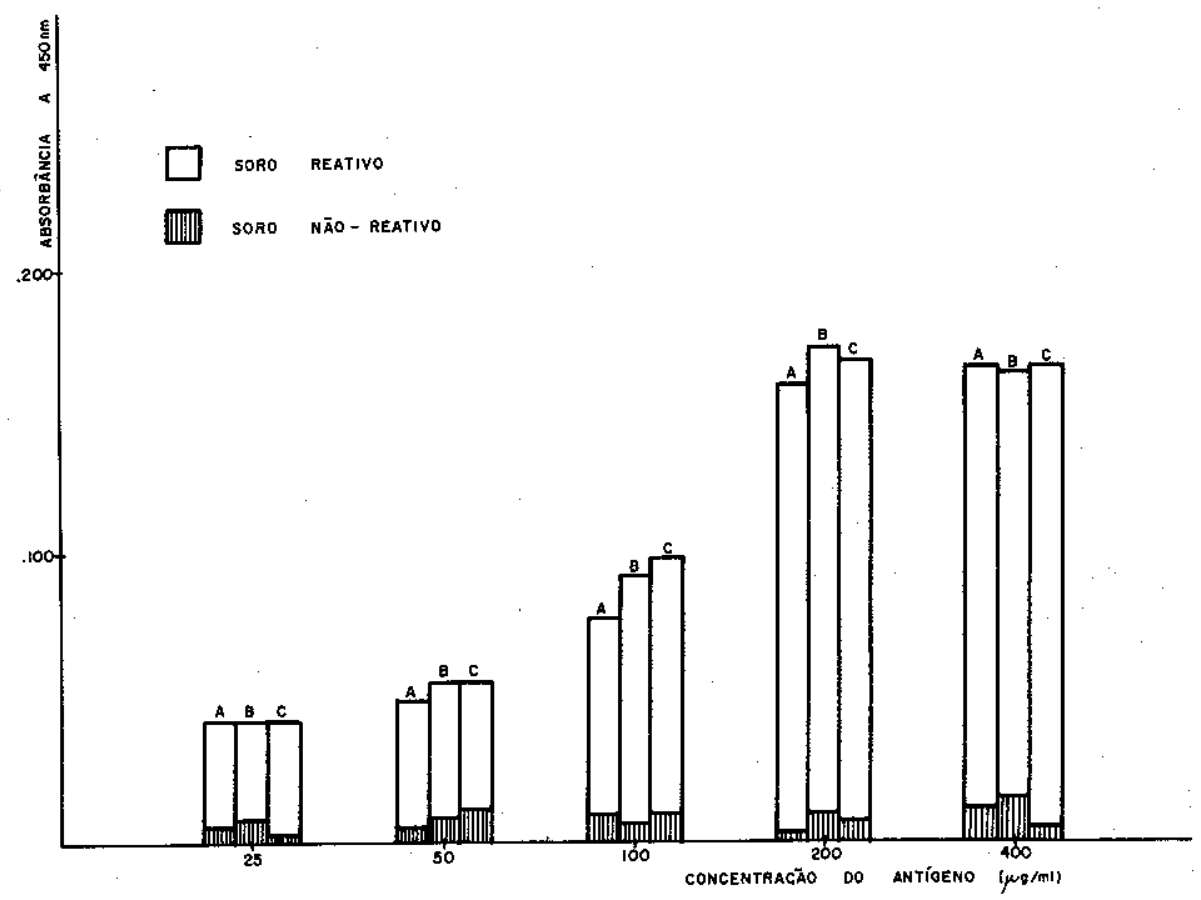

Fig. 1 - Efeito das diferentes concentraçōes protéicas do antígeno de Toxoplasma em função de diferentes quantidades de anti-IgM fixadas em fase sólida, no teste ELISA-Reverso IgM. A, B e C representam concentraçōes de, respectivamente, 100,200 e $300 \mu \mathrm{g} / \mathrm{ml}$ do anti-soro.

\section{Resultados comparativos do teste ELISA-}

\section{Reverso IgM com outros testes sorológicos}

Na Fig. 2 está representada a distribuição de titulos do teste ELISA-Reverso IgM nas amostras estudadas em comparação com os outros testes sorológicos para anticorpos IgM. A média geométrica dos títulos no teste ELISAReverso IgM foi superior à de todos os outros testes, sendo esta diferença estatisticamente significante pelo teste de Student (Tabela I). Não foi observada concordância entre os títulos dos testes por meio do coeficiente Kappa, embora fosse encontrada correlação entre eles por meio do coeficiente de Pearson.

\section{Especificidade do teste ELISA-Reverso IgM}

A especificidade do teste ELISA-Reverso IgM foi verificada testando-se 104 amostras de soros provenientes de pacientes com patologias diversas. Desse total, 27 amostras eram de pacientes com toxoplasmose crônica. Na Tabela II estão indicadas as médias das absorbâncias e os desvios-padrão obtidos em comparação com as 69 amostras de soros com toxoplasmose agu- da. Não foi encontrada reatividade cruzada em nenhuma das amostras estudadas.

\section{I S C U S S A O}

A identificação das classes de imunoglobulinas antitoxoplasma é de muita importância tanto nas infecções recentes como nas formas congênitas da toxoplasmose. A detecção dos anticorpos IgM anti-toxoplasma representa marcador sorológico importante, desde que a presença desses anticorpos pode ser utilizada para diferenciar infecções agudas das crônicas. Um aumento dos títulos hemaglutinantes equiparando-os aos títulos do teste imunofluorescênciaIgG, assim como a negativação do teste imunofluorescência-IgM, representam marcadores sorológicos entre a toxoplasmose aguda e um estágio transicional dessa infecção, como observado por CAMARGO \& LESER 5 .

O teste ELISA-Reverso para a detecção de anticorpos IgM anti-toxoplasma se comportou como um teste sensível e específico. Das 69 amostras de soros com toxoplasmose aguda estudadas, o teste ELISA-Reverso IgM apresentou títulos sistemática e significativamente 
MINEO, J. R.; CaMargo, M. E.; FERReira, A. W. \& ATMEIDA, G. - Pesquisa de anticorpos igM anti-Texoplasion gondii. por meio de técnica imunoenzimática reverss. Rev. Inst. Med. trop. Säo Paulo 28:6-11, 1986.

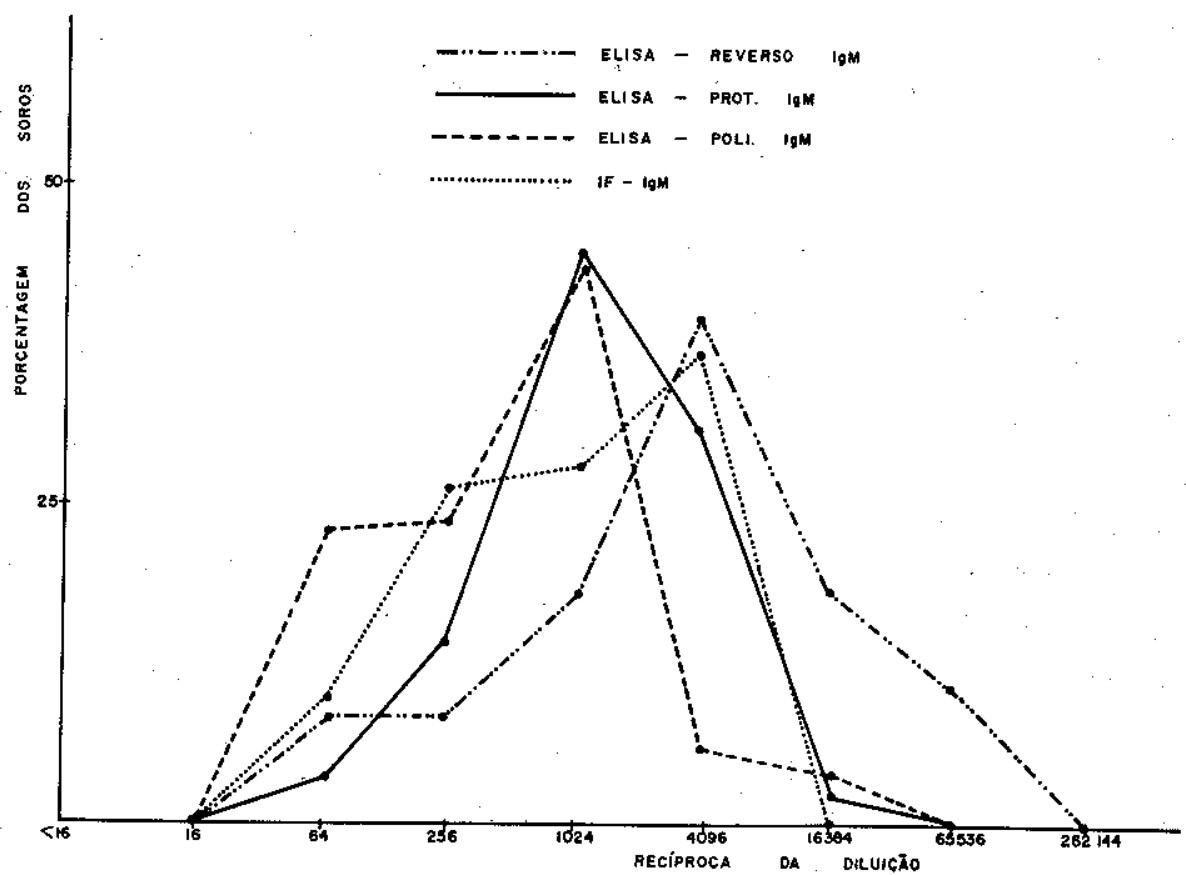

Fig. 2 - Resultados comparativos entre os títulos đos testes ELISA antigeno polissacaridico (ELISA-Poli. IgM), ELISA-IgM com antígeno protéico (ELISA-Prot. IgM) Imunofluorescência-IgM (IF-IgM) em 69 amostras de soros de pacientes com toxoplasmose "aguda".

T A B E L A I

valores das médias geométricas dos títulos codificados (MGTC) e teste " $\mathrm{t}$ " de Student para a determinaçāo da significåncia das diferenças entre elas, nos diversos testes sorológicos

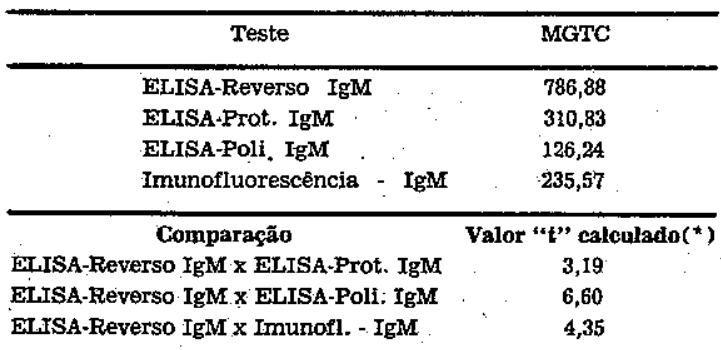

(*) Valor de " $t$ " crítico ( (para $\alpha \leq 0,05 ; 136$ graus de libercade) $=1,98$, quando " $t$ " calculado $>$ " $t$ " critico = há significáncia nas diferenças das médias

maiores do que aqueles obtidos com outros testes para anticorpos da classe IgM. Além disso, em 7 dessas amostras de soros, a positivação dos testes convencionais pàra anticorpós IgM, inclusive a do teste ELISA-IgM com antígeno polissacarídico, somente foi possivel após a remoção dos anticorpos IgG por passagem em coluna de proteina $\mathbf{A}$ ou absorção em suspensão de Staphylococcus aureus. O teste ELISAReverso IgM. no entanto, não necessitou da se-
T A B L A II

Determinaçăo da especificidade do teste BLISA-Reverso IgM am amostras de soros apresentando patologias diversas (diluição 1/16)

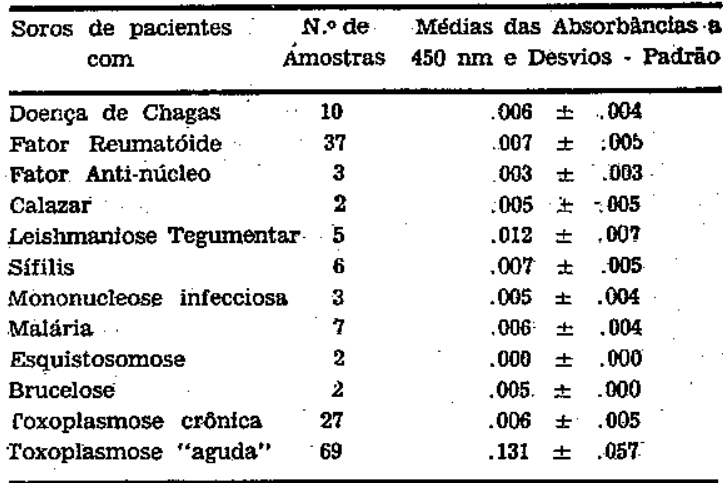

paração dos anticorpos IgG para a positivação. dessas 7 amostras de soros. Isto pode ser explicado pelo fato de que na primeira etapa do ensaio, como o imunoadsorvente so tem afinidade para as imunoglobulinas $\mathbf{M}$, os anticorpos IgG não competem pelos determinantes antigề nicos do toxoplasma. Por outro lado, resultados positivos falsos que são frequientemente observados nos soros com fator reumatóide, nāo foram encontrados no teste ELISA-Reverso 
Mineo, J. R.; CAMARgo, M. E.; FERREIRA, A. W. \& ALMEIDA, G. - Pesquisa de anticorpos IgM anti-Toxoplasma gondii por meio de técnica imunoenzimática reversa. Kev. Inst. Med. trop. S3a Fasolo 28:6-11, 1986.

IgM e isto se deve à utilização do conjugado empregando fragmento $F\left(a^{\prime}\right)_{2}$ ao invés da imunoglobulina íntegra que foi utilizado por NAOT \& REMINGTON ${ }^{13}$. A conjugação direta do antígeno com a peroxidase, como preconizado por FRANCO \& col.10, abreviando o teste imunoenzimático em uma etapa, representa uma excelente variante técnica. No entanto, como demonstrado por estes mesmos Autores 9, dependendo da escolha do método de conjugação, po de resultar em moléculas antigênicas com diferentes graus de marcação, o que ocasiona testes não-reprodutíveis além de aumentar a intensidade de coloração normalmente encontrada nos controles da reação. Ao contrário, pudemos observar que a marcação do fragmento $F\left(a b^{\prime}\right)_{2}$ resulta em controles do teste com intensidade de coloração significativamente menores, o que propicia, inclusive, a determinação dos títulos dos soros por simples leitura visual.

Em vista dos resultados obtidos concluímos que, no que diz respeito à detecção de anticorpos IgM como marcador sorológico importante na caracterização da toxoplasmose aguda, a técnica imunoenzimática reversa foi, dentre as técnicas estudadas, aquela que apresentou resultados mais satisfatórios, levando se em consideração suas propriedades de sensibilidade $\mathbf{e}$ especificidade.

\section{SUMMARY}

\section{Reverse IgM enzyme-linked immunosorbent assay (Reverse IgM-ELISA) for toxoplasmosis serodiagnosis}

A Reverse IgM enzyme - linked immunosorbent assay (Reverse-IgM ELISA) was described in which polyvinyl microplates were sensitized with anti-immunoglobulin $\mathbf{M}$ (IgM) antibodies and then sequentially allowed to react with patient's serum, Toxoplasma gondii soluble antigen, peroxidase - labeled specific $F\left(a b^{\prime}\right)_{2}$ fragment and substrat. Measurement of activity of the solid phase bound enzyme conjugate was done by spectrofotometric reading of the final developed color. In a group of 69 sera samples from individuals with recently acquired toxoplasmosis, Reverse-IgM ELISA was positive in every case, showing higher geometric mean titer than others conventional serological tests. Furthermore false-negative IgM samples presented positive Reverse-IgM ELISA results even without adsorption with Staphylococcus aureus protein A. In a group of 104 sera samples from individuals with others pathologies, no interference was observed, even in the false-positive IgM samples due to the presence of IgM rheumatoid factor.

\section{REFERENCIAS BIBIJOGRAFICAS}

1. AMBROISE-THOMAS, P.; FRANESIO, J.; SIMON, J.; MICOUIN, C. \& PIERSON, Y. - Les facteurs rheumatoids. Cause de non-especlficité de l'immunofluorescence anti-IgM dans la toxoplasmose. Ann. Biol. Clin. 38: 315-319, 1980 .

2. ARAUJO, F. G.; BARNETT, E. V. \& GENTRY, L. O. False-positive antitoxoplasma fluorescent-antibody tests in patients with antinuclear antibodies. Appl. Microblol. 22: 270-275, 1971.

3. AVRAMEAS, S. \& TERNYNCK, T. - The cross-linking of proteins with glutaraldehyde and its use for the preparation of immunosdsorbents. Immunochemistry 6: 53-66, 1969.

4. CAMARGO, M. E.; FERREIRA, A. W.; MINEO, J. R.; TAKIGUTI, C. $\mathrm{K}$. \& NAKAFIARA, O. S. - Immunoglobulin $G$ and immunoglobulin $M$ enzyme-linked immunosorbent assays and defined toxoplasmosis serological patterns. Infect. \& Immun. 21: 55-58, 1978.

5. CAMARgo, M. E. \& LeSER, P. G. - Diagnostic information from serological tests in human toxoplasmosis. II. Evolutive study of antibodies and serological patterns in acquired toxoplasmosis, as detected by hemagglutsnation, complement fixation, IgG and IgM-immunofluorescence tests. Rev. Inst. Med. trop. São Paulo 18: 227-238, 1976.

6. CAMARGO, M. E.; LESER, P. G. \& LESER, W. S. P. - Diagnostic information from serological tests in human toxoplasmosis. I. A comparative study of he magglutination, complement fixation, IgG - and IgM. immunofluorescence tests in 3,752 serum samples. Rev. Inst. Med. trop. São Paulo 18: 215-226, 1976.

7. CAMARGO, M. E.; LESER, P. G. \& ROCCA, A. Rheumatoid factors as a cause for false positive IgM anti-toxoplasma fluorescent tests. A technique for especific results. Rev. Inst. Med. trop. São Paulo 14: 310-313, 1972 .

B. ChANTLER, S.; DEVRIES, E.; ALLEN, P. R. \& HURN, B. A. L. - A rapid immunofluorescent procedure for the detection of specific IgG and IgM antibody in sera using Staphylococcus aurcus and latex-IgG as absorbents. J. Immunol. Meth. 13: 367-380, 1976.

9. FRANCO, E. L.; WALLS, K. W. \& SULZER, A. J. Reverse enzyme immunoassay for detection of specific antitoxoplasma immunoglobulin M antibođies. J. Clin. Microblol. 13: 859-864, 1981. 
MUNEO, J. R.; CAMARGO, M. E.; FERREIRA, A. W. \& ALMEMA, O. - Pesquisa de anticorpas IgA muti-Toxoplasma gondli por meio de técnica imunoenzimatica reversa. Rev. Inst. Med. trop. Săo Paxio 28:6-11. 1986:

10. FRANCO, E. L.; WALLS; K. W.; SULZER, A. J. \& SOTO, J. C. - Diagnosis of acute acquired toxoplasmosis with the onzyme - labelled antigen Reversed immunoassay for immunogiobulin $M$ antibodies. $J$. Immunoassay 4: $373-393$, 1983 .

11. MICHELI, A. \& ISLIKER, H - Cleavage of Gamma. M-globulin by means of reaucing enzyme systems: Immunochemalstry 3: $385 \cdot 392$, 1966 .

12. MINEO, J. R.; CAMARGO; M. I. \& FRRREIRA, A. W. - Enzyme-linked immunosorbent assay for antibodies to Toxoplasma gondii polissaccharides in human toxoplasmosis. Infect. \& Immun. 27: 283-287, 1980.
13. NAOT, Y \& REMINGTON,; J. S. - An engymoilthred immunosorbent assay in detection of IgM antibodtes to Toxoplasma gendit: use for disgnosis of acute acquired toxoptasmasis. J. Infect. DL. 142: 757.766, 1980.

14. WILSON, M. B. \& NAKANE, P. K. - Recent developments in the periodate method of conjugating horse. radish peroxidase (HRPO) to antibodles. $\mathrm{Kn}$ : KNAPP, W.; HOLUBAR, $K$. \& WTCK, $G$. ed. Immuntonio. rescence and Related Techniques. Ansterdam. NortHolland Blomedical, 1978, pág. 215.

Recebido para publicacha em 28-2:1685. 